\title{
LAS PELEAS DE TOROS EN AREQUIPA Y EL TORO TINKU EN POTOSÍ
}

\section{BULLFIGHTING IN AREQUIPA AND THE TINKU BULL IN POTOSI}

Edmundo Motta Zamalloa ${ }^{t}$

El paisaje arequipeño puesto en la perspectiva del tiempo no sería completo sin la campiña -de amplias terrazas de cultivo y rodeada por un anillo de volcanes-, el yaraví, la picantería, la devoción por la Virgen de Chapi, la peregrinación a su santuario y, por supuesto, las peleas de toros. Expresiones singulares que tomados en conjunto formaron parte de ese extrañamiento hegeliano en el plano de la cultura que el recordado Antero Peralta Vásquez, entre otros ilustres personajes de prosapia arequipeña, dieron en llamar mistianidad. Su artífice: un hombre de orgullo "electrizado" dedicado a la labranza de la tierra denominado loncco, mezcla de blanco español y nativo quechua; toda una institución de identidad.

Estamos mirando un poco el pasado reciente. Hoy se deja sentir el paraíso perdido, se oye algo de yaraví, en ocasiones, y voces de protesta porque el cemento ha devorado la campiña, y circulan de manera creciente por sus calles ciudadanos con nuevo perfil social, provenientes de la altiplanicie. Los rostros cambian, enhorabuena, pero nadie puede poner en duda que ha aumentado la devoción por la Mamita de Chapi y la afición por las peleas de toros que se llevan a cabo ya no tanto a campo abierto en los extramuros de la ciudad, como antaño, sino en plazas a lo Acho.

Otro tanto ocurrirá allende el Titicaca: sin el toro tinku tampoco estaría completo el paisaje cultural de la provincia de Charcas, del departamento de Potosí.

Las peleas de toros son un poco el pasado y presente de la mistianidad. Solo que respecto al futuro nos gana el escepticismo. Por mucho auge que parezca tener en el presente.

Cornamenta, trapío y una psicología de la ofensividad son los rasgos de un toro de pelea que le vienen en gran medida por una combinación de razas, formado en el cruce de los aindiados que se asentaron en las cabeceras de sierra (al igual que el caballo chojchi), tras las primeras hornadas que arribaron en barcos españoles, con los procedentes tiempo después, que dieron lugar a la raza nacional. La campiña arequipeña de extensas terrazas le puso los pañales y el trasicgo de labrar la tierra con arado le dio fortaleza. Este toro fue el primer engreído del gañán loncco. El loncco y el toro hicieron una dupla como el caballo con su jinete (chalán) en Trujillo, la llama y el indio en la altipampa, el camello con el árabe en el desierto, la serpiente con el shipibo en la Amazonía, el pescador y

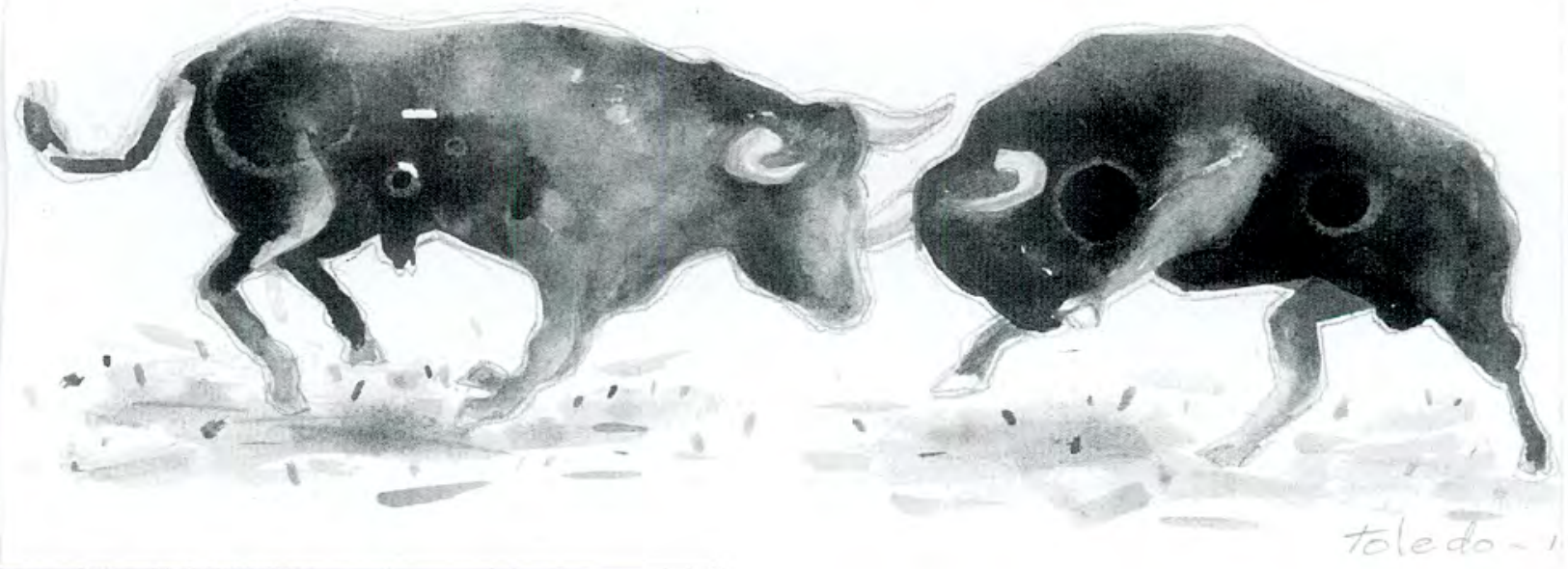


su chalana en el mar.

Hace 33 años una tesis de bachiller titulado "Ethos y sociedad agraria. Análisis del Astero de Plata", sustentado por quien escribe estas líneas en la Universidad Nacional San Agustín, se ocupó de la pelea de toros haciendo notar que era una peculiar expresión estética del agricultor arequipeño, que tomaba en su origen y configuración sus costumbres, su idiosincrasia, su lenguaje, sus amores y desamores, ingredientes indispensables volcados en ese peculiar juego que alcanzó profundidad por su capacidad simbólica de contener varias dimensiones, pues se trataba de un complejo símbolo cultural. Pablo Macera lo dio a conocer en las publicaciones a mimeógrafo que editaba en su Seminario de Historia Rural Andina de la Universidad Nacional Mayor de San Marcos, en 1982 , bajo cl título de "El Astcro de Plata". Y con cste mismo título la Pontificia Universidad Católica del Perú reprodujo en la revista Anthropológica $\mathrm{N}^{\circ} 6$, en 1986.

Una segunda aproximación desde las ciencias sociales dedicada a las peleas de toros fue la tesis de maestría de Miguel Ángel Céspedes Carpio presentada en la UNSA en el 2000, bajo el título "Las peleas de toros en la ciudad de Arequipa: Un enfoque de la Antropología". En 2011 Juan Guillermo Carpio Muñoz publicó un libro-archivo: "Surco, pasión y gloria del chacarero arequipeño y sus peleas de toros. Tratados de cultura loncca y tauromaquia arequipeña". (Contiene historia, discursos, nómina de socios de ACPATPA, texto de reglamento de peleas de toros, etcétera). Manuel Rodríguez Velásquez publicó en 1997 sus impresiones de periodista: "Las peleas de toros en Arequipa". Causaría extrañeza que siendo las peleas de toros una expresión de gran arraigo popular y antigücdad, no concitara la atención de curiosos, periodistas, artistas y estudiosos. Y no dejemos de mencionar la enorme difusión que ha logrado en los últimos quinquenios a través de revistas dedicadas en especial a las peleas de toros, filmaciones de cotejos que se ofrecen en videos, programas de televisión, visualizaciones colocadas en Youtube. Las peleas de toros han terminado por trascender la chacra y las fronteras de la Región Arequipa, extendiendo su magnetismo a un público diverso, y a la vecindad regional como los departamentos de Moquegua y Tacna, lugares donde ha prendido su buena estrella entre ganaderos y agricultores.
Un domingo cualquiera el degustador de este juego puede encontrar en algún lugar tradicional de Arequipa un espectáculo programado de peleas de toros. En treinta años ha ido ganando en estilización. Cuando recogía material para escribir mi bachillerato había una pasión efervescente por los toros, pero los aficionados no contaban con un estatuto de agremiados ni tenían un reglamento de peleas de toros, los encargados de programar los cotejos se guiaban por criterios más o menos consensuados sobre peso, edad y cxperiencia cn combate de los cornúpctas, y un par de jueces de pelea cuyos dictámenes podían ser fácilmente revertidos. Se pensaba entonces tomar como modelo el reglamento de pelea de gallos (que gozaba de gran popularidad); hoy los criadores de peleas de toros agrupados en ACPATPA tienen un Estatuto y un reglamento de pelea de toros (aprobado por primera vez en diciembre de 1991), que se puede bajar de internet. Con el paso del tiempo se ha refinado purgando algunos usos y costumbres en traslado, preparación, alimentación y cuidados del toro, y redujeron a dos los tres momentos de pelea que hace treinta años eran definidos en la propia cancha: señuelo, encuentro y fuga. Los jueces se han diversificado en comisiones específicas.

Una buena etnografía acerca de las peleas de toros está todavía por hacerse para comprender en su real magnitud el proceso que sigue, el que antecede, el durante y después de un cotejo, toda vez que un cotejo solo es el momento culminante de ese proceso; así como de su riqueza simbólica, o de las posibilidades que su proyección al futuro pone en jucgo, como el formar un toro de pelea, al igual que un gallo de riña, aislando al toro del loncco y de su contexto.

\section{EL TORO TINKU}

Tinku es una voz aymara que significa "encuentro", "lucha", por lo que "toro tinku" quiere decir pelea de toros. Es decir tauromaquia, en su verdadera acepción. La historia la occidentalizó como "corrida de toros", cuando el sentido original debió ser "pelea entre toros".

No es por quitarle exclusividad a los arequipeños, pero 33 años después de haber inquisitoriado en toros pareccría ingenuo pensar que solo el loncco convirtió una pelea de toros en fiesta. Hoy el mundo globalizado gracias a la información, pone en 


\section{La Vida y la Historia}

Motta, E. Las Peleas de Toros en Arequipa y el Toro Tinku en Potosí

tela de juicio nuestras iniciales convicciones. Hay peleas de toros en otros lugares e igualmente destinados como espectáculo. "Siéntate al Youtube para ver lindezas", diría un cibernauta. Aquí no más cruzando el Gran Lago, en Potosí, en San Pedro de Buena Vista para ser exactos, existe la presunción de que las peleas de toros no solo tienen fama internacional -pues acuden a gozar con este espectáculo turistas de Canadá, Inglaterra y otros países-, sino pasado colonial. La presencia internacional fue resaltada por Felindo Felix Barrios, vicepresidente de la Municipalidad de San Pedro de Buena Vista, en 2012. Las peleas de toros se llevan a cabo en Bolívar, en Sacaca, Acacio y otros lugares, y en cada uno de ellos la vivencian con verdadera pasión. En Paria Grande. un cantón de la Provincia de Arque en Cochabamba el Toro Tinku tiene una larga historia, remontable a la colonia. Las peleas de toros se llevan a cabo durante tres días de fiesta, aunque no distinguen los niveles preliminares, de semifondo y peleas de fondo, ni los cotejos se limitan a dos astados desde su inicio. En San Pedro de Bucna Vista los machos adultos son preparados con la debida anticipación por sus propietarios, quienes en el afán de resguardar la agresividad de los toros les privan del sucño por lo menos veinticuatro horas antes de la pelea. Los toros tienen nombre y una gran hinchada: en el 2012 el ganador fue el toro "Anaconda" que venció al campcón cochabambino "Avión", y a otros que fueron llevados de Chuquisaca.

Las peleas de toros en San Pedro de Buena Vista aparte de concitar el interés de aficionados y espectadores locales e internacionales, despiertan una verdadera pasión competitiva entre las distintas comunidades de Bolivia, quienes se movilizan kilómetros de distancia junto con sus animales para participar en la localidad sede, y cuando están en el campo de encuentro, o tinku, cruzan apuestas en dinero, rivalizan las subjetividades convirtiendo las peleas de toros en lo que C. Geertz llamaba juego profundo.

Sin darle muchas vueltas a la salteña, Evo Morales Ayma, auténtico nacionalista aymara, declaró el toro tinku, junto con la fiesta de la pascua, como "patrimonio regional, histórico, cultural y turístico del Municipio de San Pedro de Buena Vista, de la provincia de Charcas del departamento de Potosí", mediante la ley $\mathrm{N}^{\circ} 3419$, firmado y promulgado el $8 \mathrm{de}$ junio del 2006.

Quizá el punto no sea la exclusividad sobre las peleas de toros sino su singularidad. Pudiendo no ser único, el descubrimiento y la creación simultánea, o la recreación de un evento cultural, siempre juegan a favor de una identidad.

Por eso, no sería ma mala idea que el Dr. Juan Manuel Guillén Benavides, cuyo arequipeñismo se percibe "hasta los portales" y su movimicnto político se inspira en la tradición arequipeña, declare, antes que termine su periplo por los avatares de la política, las peleas de toros como patrimonio cultural de la Región Arequipa. Tampoco sería una mala idea que el médico alcalde Dr. Alfredo Zegarra hiciese lo propio creando el Musco del loncco, un digno albergue de la historia de la cultura y el arte popular arequipeños.

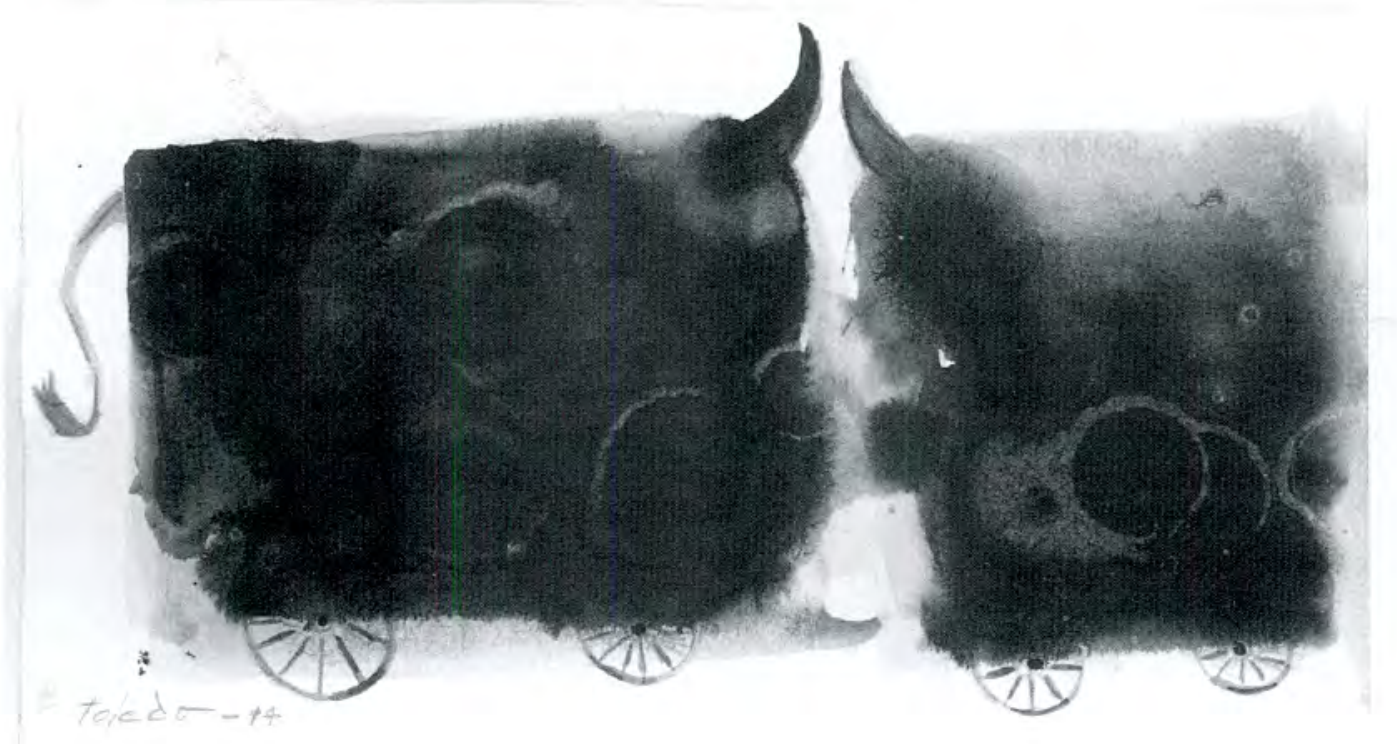




\section{NORMAS EDITORIALES Y GUÍA DE PRESENTACIÓN DE ARTÍCULOS PARA LA REVISTA LA VIDA Y LA HISTORIA}

La cdición de la Revista La Vida y la Historia es responsabilidad del Comité Editor. La cvaluación de los artículos recibidos será realizada por consultores especializados, de reconocida trayectoria en las disciplinas de la Historia y las Ciencias Sociales, quienes velarán por el cumplimiento de los normas de publicación.

\section{CRITERIOS DE PUBLICACIÓN, CITACIÓN Y REPRODUCCIÓN}

La revista La Vida y la Historia es una publicación semestral de carácter humanista, orientada a promover y difundir la investigación en el campo de la Historia y las Ciencias Sociales. Su publicación es impresa y en idioma español.

Para la publicación en la revista La Vida y la Historia los artículos presentados deben ser inćditos en forma de cnsayo, estudio o análisis.

Los artículos publicados en esta revista pueden ser citados en otros documentos, siempre y cuando se indique la siguiente información: Revista La Vida y la Historia. Tacna (Perú): Universidad Nacional Jorge Basadre Grohmann, número de la revista, página(s) y año de publicación. ISSN 2312-9115.

Si la reproducción de artículos publicados en la revista, son con fines académicos y sin ánimo de lucro, puede realizarse si se incluye la información establecida en el párrafo anterior. Si su reproducción implica otros usos, debe solicitarse autorización escrita al Director de la revista La Vida y la Historia.

La revista señala que la publicación de artículos no da derecho a remuneración alguna y que la responsabilidad del contenido de los artículos es de los autores, inclusive en lo relacionado con la propiedad intelectual de otros autores y/o fuentes.

La revista La Vida y la Historia recibe artículos de la disciplinas de Historia, Ciencias Sociales y afines.

Los artículos deben ser redactados en español, título y resumen en español e inglés, impresos en papel bond blanco de tamaño A4 (210 x 297mm), en una sola cara.

La extensión del manuscrito no debe exceder doce (12) páginas, incluyendo bibliografía, escritas en una sola cara, con caracteres de 10 puntos en estilo Times New Roman.

2. ESTILO DE PRESENTACIÓN

2.1. Secciones

- Título

- Title: Es el título traducido correctamente en idioma inglés.

- Autor/es: Si el trabajo ha sido realizado en equipo, debe colocarse como primer autor, el que tuvo mayor responsabilidad en la realización del trabajo.

- Afiliación: Institución a la cual pertenecen los autores (especificar departamento o área por cada autor)

- Resumen

- Palabras clave: No deben ser menores a dos ni mayores a cinco, ordenadas alfabéticamente.

- Abstract: Es el resumen con una correcta traducción al inglés.

- Key Word: Palabras clave correctamente traducidas al inglés.

- Texto: Contenido del Artículo.

- Agradecimiento: Incluirlos solamente si los hubiera, y solo se menciona a quienes contribuyeron con un apoyo muy importante (técnico) o las instituciones que han financiado la investigación (si fucra el caso).

- Referencias citadas o bibliográficas

Además los artículos a ser publicados, deberán cumplir los requisitos que a continuación se detalla:

2.2. De la presentación: Sc presentará 01 cjemplar impreso de un aproximado de 12 páginas y un CD. Los artículos deber ser preparados en formato MS Word utilizando la fuente Times New Romas de tamaño 10, a espacio sencillo. La primera página del artículo debe incluir: El Título (español e inglés) nombre de autor (es), afiliaciones, abstract y palabras clave. Y utilizarán la misma fucnte con distinto tamaño y estilo.

2.3. Del Tamaño y Márgenes: En tamaño A4 $(210$ x297 cm). Los márgenes deben ser configurados de la siguiente manera: superior e izquierdo: $2.5 \mathrm{~cm}$; inferior y derecho: $2 \mathrm{~cm}$. No se permite agregar pie de página ni cncabczados. Las referencias bibliográficas sc agregarán al finalizar cl texto.

2.4. Del Título y Autores: El título será escrito en español y en inglés, en tamaño 16 y negrita en mayúscula y centrada respetando la redacción de las denominaciones de nombres científicos (si los hubiera) Además debe ser claro y conciso. El nombre(s) de autor(es) cn tamaño 12 y negrita; la afiliación o institución/árca a la que pertenece por cada uno de los autores, dirección y correo electrónico (tamaño 12) deben estar centrados.

2.5. Del Resumen: Resumen (Abstract) del artículo y palabras clave, español y en inglés. Cada artículo debe incluir un resumen de no más de 200 palabras cn la primera página, scguido por una lista de palabras clave. El resumen debe ser conciso y las palabras clave deben estar justificadas de ambos lados (izquierdo y derecho).

Redactado en un promedio de 200 a 250 palabras. Se redacta en tiempo pasado. Debe ser escrito en un solo párrafo, separando las oraciones con punto scguido. Sólo las palabras clave deben ir como punto aparte. 
2.6. Del Texto: Estará escrito en dos columnas.

2.7. De las Seciones: El título de una sceción debe estar en fuente Times New Roman, tamaño 10 y en negrita, escrito con letras mayúsculas. Debe estar alineado a la izquierda a partir de la introducción, excepto las referencias bibliográficas.

2.8. De las Subdivisiones: El título de las subdivisiones debe estar alineado a la izquierda. La fuente a utilizar es Times New Romas tamaño 10 y en negrita y sólo las letras iniciales de cada palabra serán escritas en mayúscula.

2.9. De las Figuras o Tablas: Podrá incluirse fotografias, gráficos, tablas o imágenes, etiquetándolos como figuras o tablas segín convenga.

Las figuras serán identificadas con la etiqueta Figura $\mathrm{N}^{\circ}$, numeradas con números arábigos de manera consecutiva, la cual será ubicada al pie de la figura. Las figuras, deberán adjuntarse adicionalmente como archivo de imagen (jpg o png).

Las tablas serán identificadas con la etiqueta Tabla $\mathrm{N}^{\circ}$, mumeradas con números arábigos de manera consecutiva y ubicada en la cabecera de la tabla de forma centrada.

Las figuras y tablas a ntilizar deberán ser insertadas en el punto apropiado del texto, debe ser mencionada en cl texto al menos una vez y antes de su aparición.

2.10. Del Idioma, Estilo y Contenido: Los artículos deben presentarse en español. El título y el resumen están inscritos en español c inglés. La ortografía y puntuación deben escribirse con estilo sencillo y directo. Utilice estructuras simples para las oraciones, así como vocabulario común y básico. Defina o explique el vocabulario técnico con sencillez. Explique acrónimos cuando aparezcan en el texto por primera vez. Por ejemplo "Acadenia Internacional del Trabajo (AIT)".

La presentación de unidades de medida y valores muméricos se realizará conforme al Sistema Internacional de Unidades, asimismo, debe utilizarse la coma ", " para la separación decimal.

2.11. De las Referencias y Citas: Utilizar el estilo de referencias bibliográficas de la norma APA. Deben aparecer solamente las referencias bibliográficas utilizadas por el autor en la realización del estudio o investigación y que son mencionadas en la redacción del artículo. Serán presentadas en el orden alfabético. Considerar que si eu el artículo hay quince citas, también debe haber quince referencias bibliográficas.

\section{IMPORTANTE:}

Los autores son responsables de ascgurarse que su trabajo sca conducido de una mancra responsable y ćtica. La estructura y estilo son tan importantes como el contenido. Antes de escribir su artículo, le recomendamos que lea la amplia literatura disponible para informarse respecto a cómo escribir un buen artículo técnico.

\section{PROCESO DE RECIBO, SELECCIÓN Y EVALUACIÓN}

3.1. Recepción de los artículos.- Las convocatorias para la recepción de artículos se cierran el 30 de abril y 30 de setiembre de cada año. Los artículos se entregan en formato impreso en la Oficina General de Investigación de la Universidad Nacional Jorge Basadre Grohmamn sito en Ciudad Universitaria Av. Miraflores s/n, Tacna, Perú, o son enviados mediante correo electrónico a la cuenta coin amjbg.edu.pe. Junto al artículo (construido en un procesador de textos y guardado en formato doc o .docx) se envían las figuras presentadas en él, debidamente identificadas (en formato jpg o png con alta calidad), y los datos de los autores debidamente diligenciados según formato.

El formato impreso debe enviarse mediante carta de presentación acompañada del artículo original impreso en papel, más un CD en formato de procesador de textos.

3.2. Proceso de selección.- Para que un artículo sea admitido en la revista La Vida y la Historia debe cumplir con los parámetros de forma establecidos por la revista. Los autores que decidan retirar sus artículos del proceso de selección, no implica que pierdan la posibilidad de presentarlo para ediciones futuras. En los artículos que a pesar de ser aceptados, se detecte algún tipo de plagio no serán adnitidos para la impresión final. Después de un tiempo prudencial, el director del comité cditorial comunicará al autor sobre la accptación de su artículo.

3.3. Proceso de Evaluación.- La primera evaluación la realiza el Comité Editorial, sobre el cumplimiento de los requisitos formales y la adecuación al interés temático de la Revista, de la cual se envía un mensaje a los autores donde se señala su resultado. En caso de corresponder al interés de la revista, se indican a los autores que aquellos aspectos a ajustar y la fecha límite para hacer la nueva entrega.

Comprobado el cumplimiento de los requisitos formales, el artículo es de forma confidencial. El resultado de la evaluación se informa a los autores oportumamente mediante correo electrónico, y en caso de requerirse, se indica la fecha para la entrega de los documentos ajustados, con el fin de que los árbitros emitan su concepto definitivo sobre la condición de publicable o no. 